\title{
Anàlisi química de diversos components de la Coca-Cola
}

\author{
Jordi Banús Martí, Oscar Núñez Burcio i Irene Miquel Plana \\ Institut Numància, Santa Coloma de Gramenet (Barcelona) \\ imiquel2@xtec.cat
}

En aquest treball de recerca s'han utilitzat tècniques analítiques senzilles que ens han permès trobar la quantitat de diversos components de la Coca-Cola. Mitjançant mesures de densitat s'ha determinat el contingut de sucre, a través d'una valoració àcid-base s'ha trobat la concentració d'àcid fosfòric, i la concentració de cafeïna s'ha determinat pel mètode d'extracció líquid-líquid.

Paraules clau: coca-cola, anàlisi química, densitat, sucre, àcid-base, extracció líquid-líquid

\section{Introducció}

La Coca-Cola és potser la beguda més coneguda del món i, com a tal, ha estat sempre envoltada d'un seguit de mites i llegendes que la fan encara més interessant i atractiva. A més a més, la seva composició química dóna joc per realitzar una gran quantitat de pràctiques i experiments, alguns dels quals es poden adaptar al currículum de secundària o batxillerat. En aquest treball de recerca s'ha utilitzat la beguda de cola amb un triple objectiu:

- Per un costat, aprendre com es treballa en un laboratori analític.

- Per altra banda, aplicar alguns dels conceptes estudiats a classe a la realització de diverses pràctiques de laboratori.

- I finalment i mitjançant l'obtenció d'alguns dels seus components, comprovar que la fórmula de la Coca-Cola no és en realitat tan secreta.

Les pràctiques que s'han dut a terme en aquest treball han estat tres.

Primerament s'ha trobat la concentració de sucre de la Coca-Cola classic i de la Coca-Cola light mitjançant mesures de densitat i s'han comparat aquests dos valors.

En segon lloc s'hi ha trobat la concentració d'àcid fosfòric a través d'una valoració àcid-base. Aquestes dues pràctiques s'han pogut realitzar en el laboratori de l'institut.
Per últim i per a trobar la concentració de la cafeïna s'ha comptat amb l'ajuda del Dr. Òscar Núñez de la Facultat de Química de la Universitat de Barcelona on s'hi ha realitzat una extracció líquidlíquid.

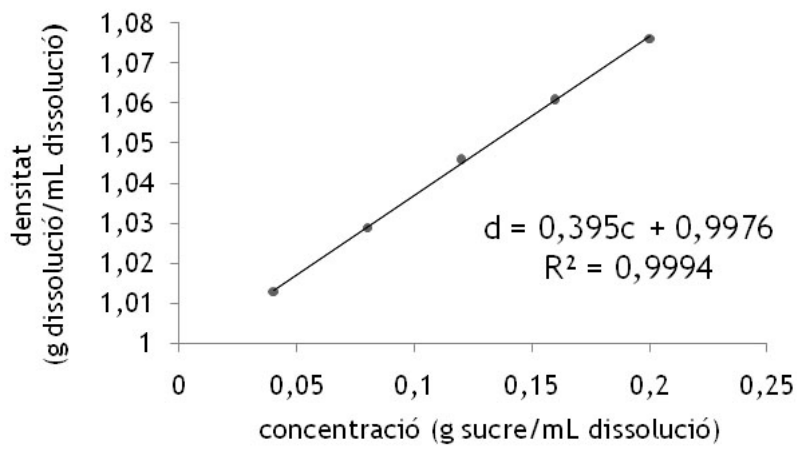

Figura 1. Recta de calibratge de cinc mostres patró d'aigua amb sucre.

\section{Determinació del contingut de sucre de la Coca-Cola}

Per determinar la concentració de sucre de la Coca-Cola s'ha elaborat prèviament una recta de calibratge de la densitat en funció de la concentració de sucre. Per fer-ho s'han preparat diversos patrons de dissolucions d'aigua amb sucre, tot modificant en cadascuna la quantitat de sucre i deixant 
constant el volum d'aigua a fi d'obtenir mostres de densitats i concentracions diferents. Posteriorment s'ha calculat la densitat de cada una de les mostres i s'ha construït la recta de calibratge de la densitat en funció de la concentració (fig. 1).

El següent pas ha estat calcular la densitat de la Coca-Cola classic i de la Coca-Cola light (prèviament desgasificades) mesurant el pes de $100 \mathrm{ml}$ de cada mostra. Finalment, mitjançant la recta de calibratge s'ha obtingut la concentració de sucre de cada mostra (taula 1).

\begin{tabular}{|l|c|c|}
\cline { 2 - 3 } \multicolumn{1}{c|}{} & $\begin{array}{c}\text { Coca-Cola } \\
\text { Classic }\end{array}$ & $\begin{array}{c}\text { Coca-Cola } \\
\text { Light }\end{array}$ \\
\hline Matràs buit $(\mathrm{g})$ & 54,8 & 54,8 \\
\hline Matràs ple $(\mathrm{g})$ & 159,0 & 154,8 \\
\hline Massa dissolució $(\mathrm{g})$ & 104,2 & 100 \\
\hline Volum dissolució $(\mathrm{g})$ & 100 & 100 \\
\hline Densitat $(\mathrm{g} / \mathrm{mL})$ & 1,042 & 1 \\
\hline Concentració $(\mathrm{g} / \mathrm{mL})$ & 0,112 & 0,006 \\
\hline
\end{tabular}

Taula 1. Càlcul de la concentració de sucre en diverses begudes de Coca-Cola

Com es pot veure a la taula 1, la concentració de sucre de la Coca-Cola light és pràcticament zero, tal com es podia esperar. En canvi la Coca-Cola classic conté una elevada quantitat de sucre $(0,112$ $\mathrm{g} / \mathrm{mL}$ ). Si es calcula el contingut de sucre d'una llauna de $33 \mathrm{cL}$ corresponen a $36,96 \mathrm{~g}$, un valor molt similar al que indica l'etiqueta de la llauna.

\section{Determinació del contingut d'àcid fosfòric a la Coca-Cola}

Per a determinar-hi el contingut d'àcid fosfòric s'ha realitzat una valoració àcid-base. Com que el color fosc de la Coca-Cola hi interferia, no s'ha pogut utilitzar un indicador per trobar el punt d'equivalència sinó que s'ha construït la corba de valoració amb l'ajut d'un pH-metre i s'ha determinat el punt d'equivalència matemàticament. La solució bàsica que s'ha utilitzat per neutralitzar l'àcid fosfòric ha estat d'hidròxid de sodi. Com que la corba de valoració només s'ha portat a terme fins a neutralitzar el primer dels protons de l'àcid fosfòric, la reacció que ha tingut lloc ha estat:

$$
\mathrm{NaOH}+\mathrm{H}_{3} \mathrm{PO}_{4} \rightarrow \mathrm{NaH}_{2} \mathrm{PO}_{4}+\mathrm{H}_{2} \mathrm{O}
$$

Per realitzar l'experiència s'ha preparat una dissolució d'NaOH 0,017 M que s'ha emprat per valorar $25 \mathrm{~mL}$ de Coca-Cola classic prèviament desgasificada.
A la fig. 2 és pot observar quin ha estat el muntatge experimental utilitzat. Observem que s'ha utilitzat una bureta, un $\mathrm{pH}$-metre prèviament calibrat on es llegeixen els valors del $\mathrm{pH}$ a mesura que es va afegint dissolució d'NaOH, un vas de precipitats on hi ha la dissolució de Coca-Cola, i un agitador magnètic. A la fig. 3 es pot observar la corba que s'ha obtingut en la valoració del $\mathrm{pH}$ de la CocaCola amb hidròxid de sodi.

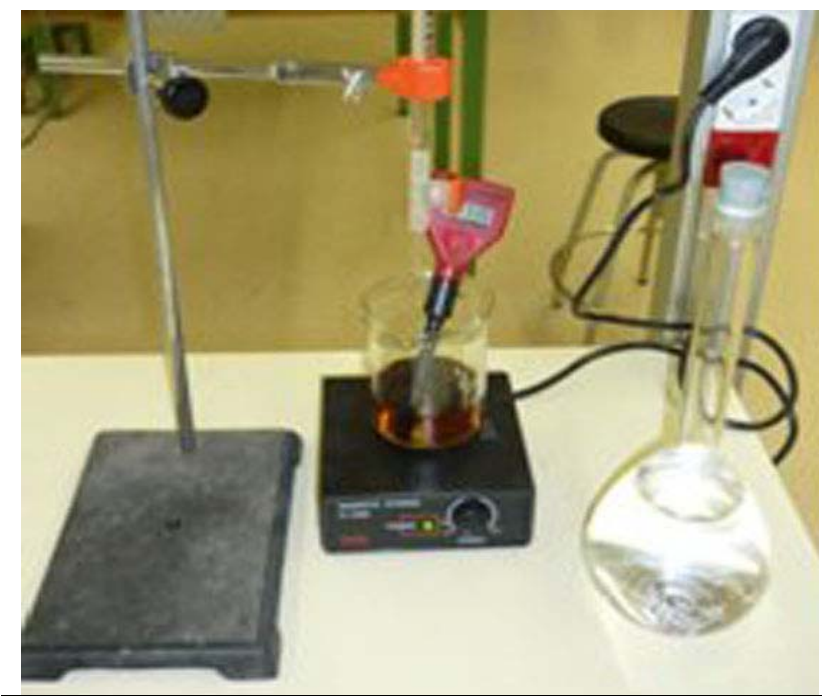

Figura 2. Muntatge experimental utilitzat per a realitzar la corba de valoració de l'àcid fosfòric de la Coca-Cola amb hidròxid de sodi.

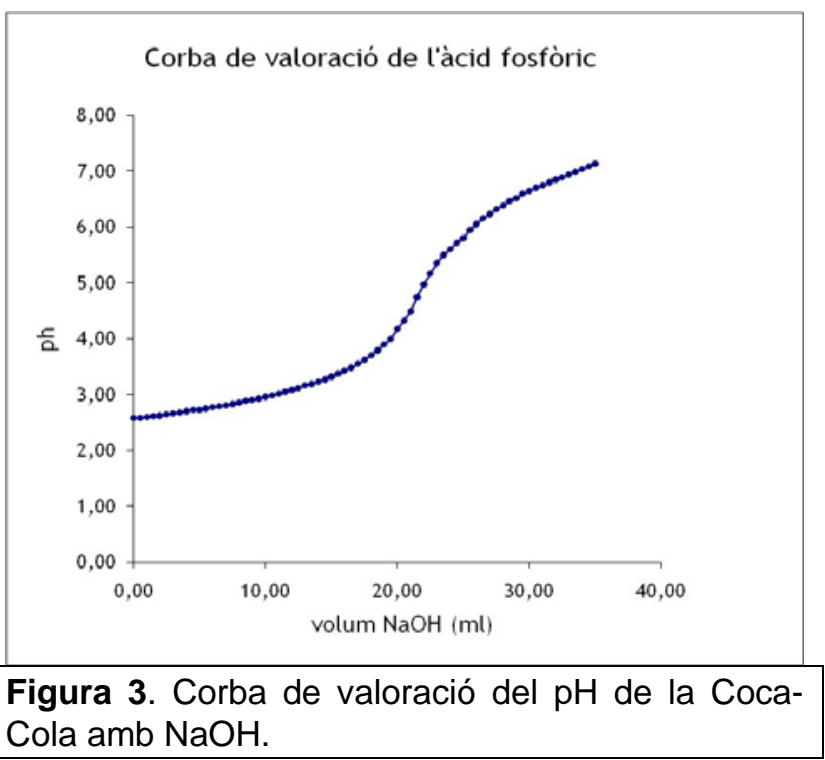

El punt de la corba en què els mols de $\mathrm{NaOH}$ neutralitzen el primer protó del $\mathrm{H}_{3} \mathrm{PO}_{4}$ és aquell en què el pendent de la corba és màxima. Per calcular 
amb exactitud quin és aquest punt s'ha calculat el pendent de la corba en cada interval. Aquest pendent equival a la derivada de la funció en aquest punt. El punt de pendent màxim obtingut (corresponent al punt d'equivalència de mols) es troba quan s'hi han afegit $21 \mathrm{~mL}$ de dissolució d'NaOH (tal com també s'aprecia a la gràfica). A partir d'aquesta dada s'ha pogut trobar la concentració d'àcid fosfòric a la Coca-Cola, valor que correspon a $9 \cdot 10^{-3} \mathrm{M}$. Si utilitzem aquesta dada per calcular la quantitat de àcid fosfòric que hi ha en una llauna de $33 \mathrm{cL}$, obtenim un valor de 0,318 g.

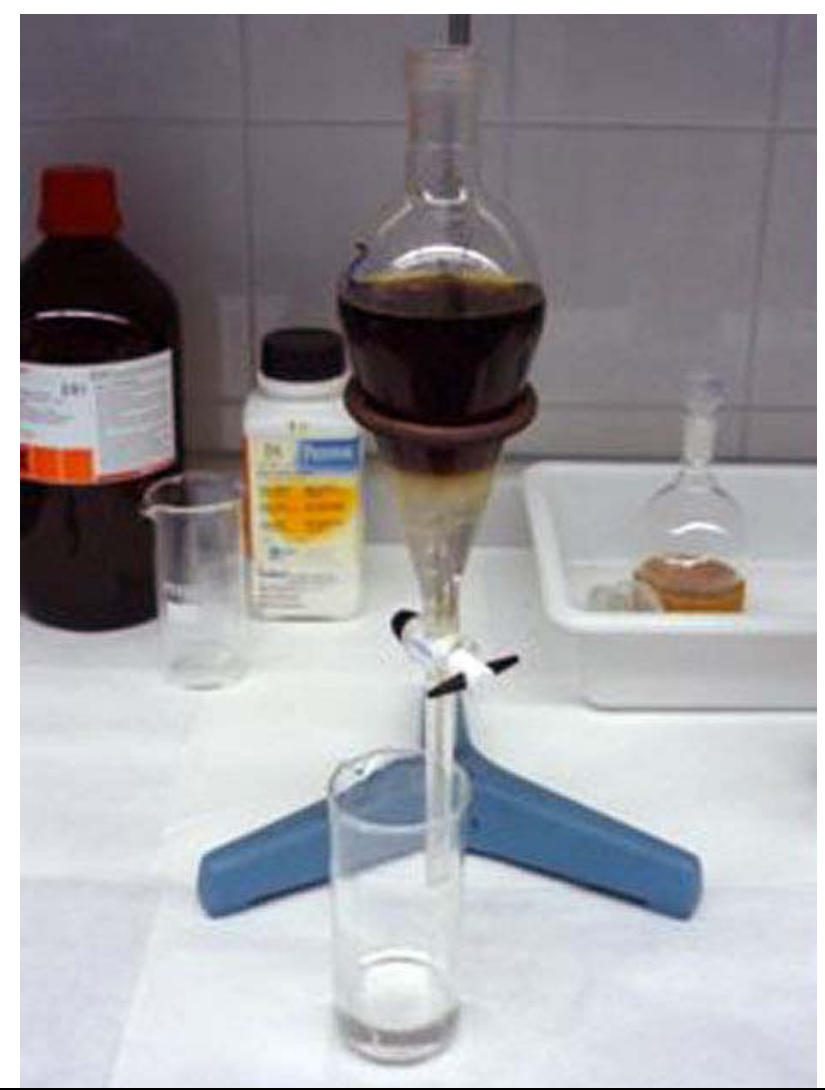

Figura 4. Embut de decantació en el que es realitza l'extracció de la cafeïna de la Coca-Cola amb clorur de metilè.

\section{Determinació del contingut de cafeïna d'una Ilauna de Coca-Cola}

Un dels components més coneguts de la CocaCola és la cafeïna. En aquesta última experiència extraurem i determinarem la quantitat de cafeïna que hi ha en una llauna de Coca-Cola classic. La tècnica analítica que s'utilitzarà serà l'extracció líquid-líquid i es basa en el fet que la cafeïna és més soluble en un dissolvent orgànic com el clorur de metilè $\left(\mathrm{CH}_{2} \mathrm{Cl}_{2}\right)$ que en l'aigua en la que es troba dissolta quan forma part del refresc.

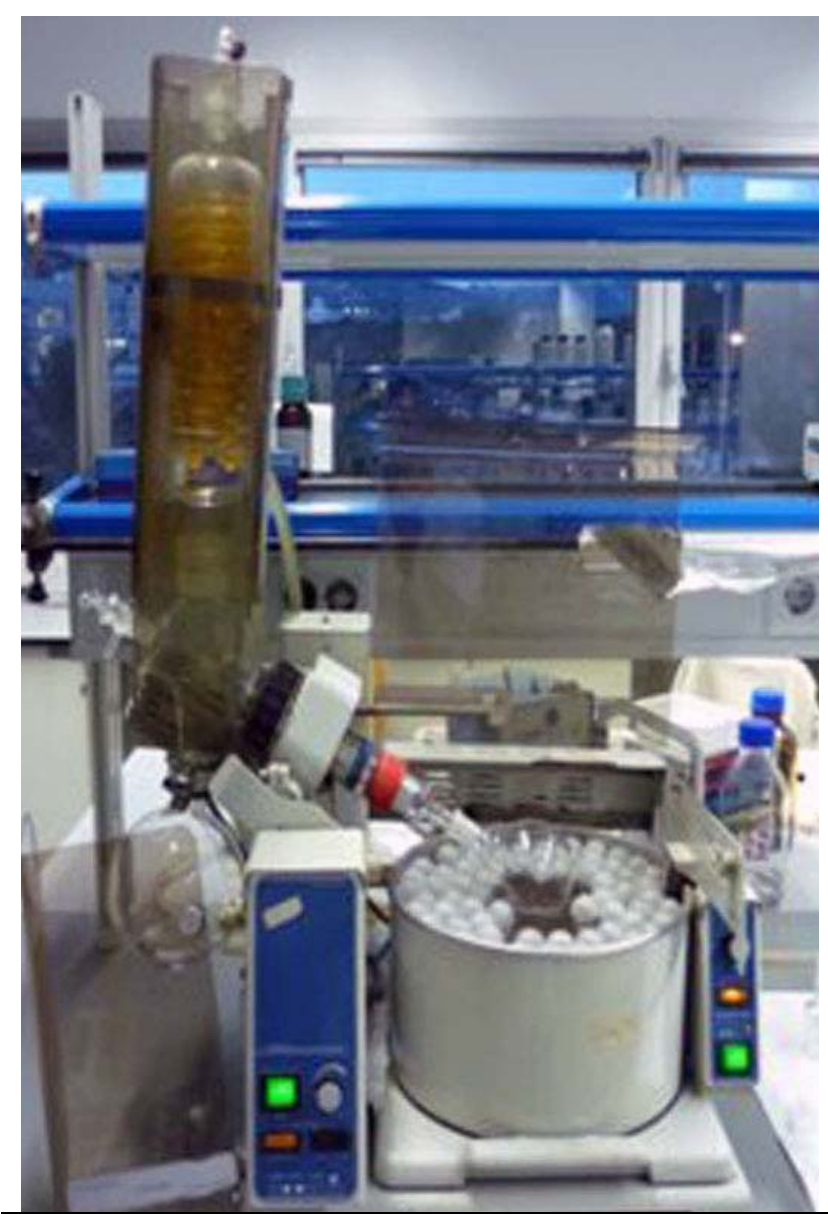

Figura 5. Rotavapor que ens permetrà separar la cafeïna del clorur de metilè.

En primer lloc i tal com hem realitzat en les experiències anteriors s'ha de desgasificar la CocaCola. A continuació s'utilitza un embut de decantació per barrejar mitja llauna de Coca-Cola amb 25 $\mathrm{mL}$ de clorur de metilè. Un cop s'ha agitat la barreja, es deixa reposar per tal que es separin les dues fases: l'aquosa formada per la Coca-Cola i l'orgànica, formada pel clorur de metilè, on s'haurà transferit gran part de la cafeïna, tal com s'observa a la fig. 4. Finalment a través de la clau de l'embut s'extreu la fase orgànica de l'aquosa. Aquest pas es realitzarà 3 vegades per tal d'assegurar-nos que tota la cafeïna passi a la fase orgànica. Un cop reunits els 3 fragments de fase orgànica, s'eliminarà la interfase amb $10 \mathrm{~mL}$ de dissolució saturada de $\mathrm{NaHCO}_{3}$ i s'assecarà (s'eliminaran les possibles restes d'aigua que hi hagin pogut quedar) amb $\mathrm{Na}_{2} \mathrm{SO}_{4}$ anhidre que posteriorment és separarà del líquid per filtració. Tot aquest procediment s'ha de realitzar una altra vegada amb l'altra meitat de la 
Coca-Cola; al finalitzar s'han d'unir els dos volums obtinguts de fase orgànica. En aquest punt de la pràctica tenim, doncs, tota la cafeïna d'una llauna de $33 \mathrm{cL}$ dissolta en el clorur de metilè. Per tal de separar-la'n s'utilitza un rotavapor (fig. 5). Aquest aparell funciona disminuint la pressió del vapor de la dissolució i escalfant-la. D'aquesta manera el dissolvent orgànic s'evapora fàcilment quedant-hi només un residu sòlid, que és la cafeïna. Com que prèviament s'ha tarat el baló que s'ha utilitzat per a rotavaporar la fase orgànica, ara es pot calcular el pes de la cafeïna obtinguda d'una llauna de CocaCola de $33 \mathrm{cL}$ i que resulta ser de 0,02987 g. S'observa que la cafeïna té forma de pols cristal-lina de color blanc.

\section{Valoració dels resultats obtinguts i perspectives per a la pràctica docent}

Aquest treball de recerca ha permès a l'alumne relacionar els continguts teòrics estudiats a l'assignatura de química de $2 n$ de Batxillerat amb una aplicació pràctica, com és trobar els components d'un refresc de cola. A més, li ha estat molt útil per a familiaritzar-se amb els trets bàsics del mètode científic: recerca d'informació, establiment d'una hipòtesis i d'un pla de treball, realització de diverses experiències de laboratori i per tant presa de contacte amb el treball experimental, utilització d'eines TIC per a l'anàlisi de dades obtingudes i finalment valoració dels resultats i formulació de conclusions.

A més a més, el fet que la mostra amb que s'ha treballat és un refresc molt conegut li ha servit per relacionar els conceptes teòrics estudiats a classe amb les seves aplicacions pràctiques i que sovint són utilitzades en els laboratoris d'anàlisis.

\section{Agraïments}

Departament de Química Analítica. Facultat de Química (UB).

\section{Bibliografia}

BANÚS MARTÍ, J. (2010). Coca-Cola, la beguda que va canviar el món. Treball de recerca. 